\title{
An analytical model of population level chronic conditions and COVID-19 related hospitalization in the United States
}

\author{
Biplab K. Datta ${ }^{1,2^{*}}$, Benjamin E. Ansa ${ }^{2}$ and Varghese George ${ }^{1}$
}

\begin{abstract}
Background: The surge in the COVID-19 related hospitalization has been straining the US health system. COVID-19 patients with underlying chronic conditions have a disproportionately higher risk of hospitalization and intensive care unit (ICU) admission. We developed a retrospective analytical model of COVID-19 related hospitalizations and ICU admissions linked to each of the three major chronic conditions - hypertension, diabetes, and cardiovascular diseases (CVD).

Methods: Based on the differential probability of hospitalization of the COVID-19 patients with and without a chronic condition, we estimate a baseline cumulative hospitalization rate and ICU admission rate using the population level chronic condition prevalence from the 2019 Behavioral Risk Factor Surveillance System survey. Next, we estimate the hospitalization and ICU admission rates under an alternative scenario of a lower prevalence of the same chronic condition, aligned with the World Health Organization target of $25 \%$ relative reduction of prevalence by 2025 . We then compare the outcomes of the baseline and the alternative scenarios.

Results: We estimate that the lower prevalence of hypertension would have lowered the cumulative hospitalization and ICU admission rates by more than 2.5\%. The lower prevalence of diabetes and CVD would lower the cumulative hospitalization rate by $0.6 \%$ and $1.4 \%$ respectively. The decrease in the rates would have been relatively higher among Black and elderly (age 55+).
\end{abstract}

Conclusions: Our model, thus, provides evidence on the importance of prevention, control, and management of chronic conditions to lessen the overwhelming financial and public health burden on the health system during a pandemic like the COVID-19.

Keywords: Chronic conditions, COVID-19, Hospitalization, ICU admission, Hypertension, Diabetes, CVD

\section{Background}

Apart from cancer, heart disease and diabetes are the leading causes of deaths and disabilities in the United States (US) population [1]. Heart disease, stroke and other cardiovascular diseases (CVD), for which hypertension is a major risk factor, account for nearly one-third of all deaths

*Correspondence: bdatta@augusta.edu

${ }^{1}$ Department of Population Health Sciences, Medical College of Georgia at Augusta University, Augusta, GA, USA

${ }^{2}$ Institute of Public and Preventive Health, Augusta University, Augusta, GA, USA

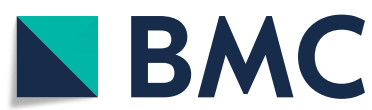

in the US [2]. One in every three US adults (age 18+) have hypertension and about $13 \%$ have diabetes $[2,3]$. The risk of COVID-19 mortality is significantly greater among those with CVD, hypertension, and diabetes [4] and the population level prevalence rates of these chronic conditions are linked to COVID-19 related hospitalization, which is also higher among patients with these underlying conditions [5].

Studies on the COVID-19 related hospitalization mostly examined the odds of hospitalization and mortality among hospitalized patients by demographic characteris-

(c) The Author(s). 2022 Open Access This article is licensed under a Creative Commons Attribution 4.0 International License, which permits use, sharing, adaptation, distribution and reproduction in any medium or format, as long as you give appropriate credit to the original author(s) and the source, provide a link to the Creative Commons licence, and indicate if changes were made. The images or other third party material in this article are included in the article's Creative Commons licence, unless indicated otherwise in a credit line to the material. If material is not included in the article's Creative Commons licence and your intended use is not permitted by statutory regulation or exceeds the permitted use, you will need to obtain permission directly from the copyright holder. To view a copy of this licence, visit http://creativecommons.org/licenses/by/4.0/. The Creative Commons Public Domain Dedication waiver (http://creativecommons.org/publicdomain/zero/1.0/) applies to the data made available in this article, unless otherwise stated in a credit line to the data. 
tics such as age, sex, race, ethnicity, etc., and underlying health conditions [6-11]. While these studies provide important insights on the association between COVID-19 related hospitalization and health conditions by assessing the demographic, social and health determinants of hospitalization, there is a dearth of analysis on how progress in the population level management of chronic diseases would have lessened the burden of COVID-19 related hospitalization.

The health systems in many communities are overwhelmed by the surge in COVID-19 cases resulting in higher demands for hospital beds, medical staff, and supplies needed to provide adequate care for both COVID-19 and non- COVID-19 patients. The intensive care units (ICU) are also overwhelmed from the increasing demands for resources necessary for patient care. Patients with other conditions who normally should have been admitted to the ICU may be replaced for seriously ill COVID19 patients. Hospitals reaching near capacity and being overflowed with COVID-19 patients thereby pose a big concern to the health system. Given the strong association between the underlying chronic health conditions and COVID-19 related hospitalizations, a question naturally arises about by what magnitude the hospitalization and ICU admission rates related to COVID-19 would have been lowered if the prevalence of some chronic conditions were lower than the status quo. This study aimed to answer this question by developing an analytical model of COVID-19 related hospitalizations linked to the population level prevalence of some chronic conditions.

Investigating this issue has important public health implications. The estimated public health burden of chronic conditions often motivates policies to effectively manage chronic diseases and thereby improving population health [12]. Quantifying the extent of hospitalization and ICU admission that could have been averted from a lower (than status quo) chronic condition prevalence, therefore, may convey an important message for strategizing effective interventions. In doing so, we separately linked three major chronic conditions (hypertension, diabetes, and CVD) in the US with COVID-19 related hospitalizations and approximately replicate the cumulative hospitalization rate for the period March 07, 2020 to January 02, 2021, reported by the Centers for Disease Control and Prevention (CDC). We then examined what could have been the hospitalizations and subsequent ICU admissions under a lower prevalence of the respective chronic conditions in adult (age 18+) population. Understanding this concept is important as it underscores the prevention and control of chronic diseases for reducing the burden of healthcare systems during a pandemic. The findings of this study contribute to existing efforts for effective management of chronic diseases at the popula- tion level and to streamline health system preparedness for managing similar pandemics.

\section{Methods \\ Model framework}

We develop a retrospective analytical model of COVID-19 related hospitalization and subsequent ICU admission for the US adult population, as a function of the prevalence of a given chronic condition. Using our model, we estimate the hospitalization and ICU admission rate per 100,000 population, specific to three major chronic conditions in US population - hypertension, diabetes, and CVD. The model links the prevalence of a chronic condition by state, race, and age-group, with the number of hospitalization and ICU admissions across these groups. The results are driven by the variations in model parameters across the state, race, and age-group.

The model follows a simple framework where a portion of the population is tested for COVID-19, a portion of the COVID-19 positive patients gets admitted in the hospital, and a portion of the hospitalized COVID-19 patients receives ICU care. Several assumptions, supported by data and the findings from existing literature, are used within this framework to replicate the COVID-19 related cumulative hospitalization rates among adults in the USA from the week ending March 07, 2020 to the week ending January 02,2021 . We begin with the assumption that the probability of being tested for COVID-19 varies across states. For example, someone residing in New York has a larger probability of receiving a COVID-19 test compared to someone residing in Kentucky [13]. Second, the probability of COVID-positivity among those who receive a test varies across race and age-group. This is because of the disproportionate risk of exposure associated with the social and economic factors such as occupation and housing [14]. Third, among the patients tested COVIDpositive, the rate of hospitalization varies by age-group and whether the patient has an underlying chronic condition or not [5]. Fourth, the presence or absence of the chronic condition is associated with individual's agegroup, race, and state of residence [15]. Stated differently, the prevalence of certain chronic condition varies across state, race, and age-group. Finally, the probability of ICU admission also varies across age-group [16] and race.

Based on these assumptions, the flow of the model is as follows: A sample from the state's adult population is tested for COVID-19, a subset of those tested positive are hospitalized, and a subset among the hospitalized patients are admitted in the ICU (Fig. 1). The primary mechanism of the model is that whether a COVID-19 patient would require hospitalization depends on whether that patient has the underlying chronic condition or not. This essentially entails the assumption that a COVID-19 patient is 


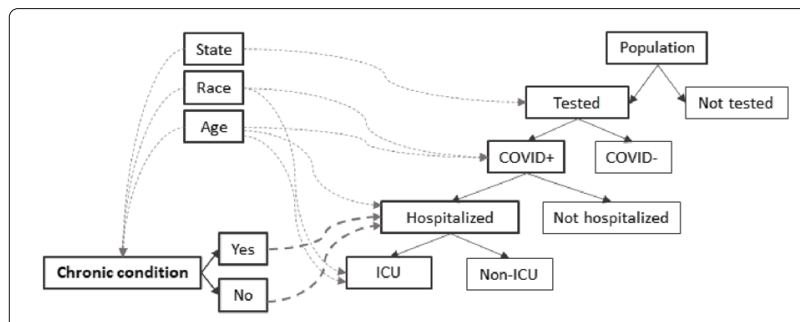

Fig. 1 Model framework. The solid lines (with arrowheads) represent flow from one stage to subsequent stage within the framework (e.g., from being COVID positive to hospitalized). The dashed lines (with arrowheads) represent probabilistic variation due to demographic (i.e., state of residence, race, and age) and health (i.e., hypertension, diabetes, or CVD) factors (e.g., probability of being COVID positive varies by race and rage)

provided with hospital care as deemed needed (and prioritized based on health condition) by the physicians. The model is separately implemented for the three chronic conditions. The adult population in the model is divided in six age groups - 18-24, 25-34, 35-44, 45-54, 55-64 and 65+; and four racial categories - White, Black, Hispanic, and Other (American Indian, Asian, Native Hawaiian/ Pacific Islander, multiracial and other), across the 50 US states and the District of Columbia.

\section{Model calculation}

Let $H_{s, r, a}$ be the number of COVID-19 related hospitalization and $I C U_{s, r, a}$ be the number of ICU admissions among individuals of race $r$ and age-group $a$ in state $s$. The hospitalization and ICU admission rates are defined as follows:

$$
\frac{H_{s, r, a}}{\operatorname{pop}_{s, r, a}}=t_{s} * v_{r, a} *\left[c_{s, r, a} * h_{c, a}+\left(1-c_{s, r, a}\right) * h_{n o c, a}\right] * 100,000
$$

$\frac{I C U_{s, r, a}}{\operatorname{pop}_{s, r, a}}=i_{r, a} * t_{s} * v_{r, a} *\left[c_{s, r, a} * h_{c, a}+\left(1-c_{s, r, a}\right) * h_{n o c, a}\right] * 100,000$

where, pop $_{s, r, a}$ is the population size of race $r$ and agegroup $a$ in state $s, t_{s}$ is the probability of being tested in state $s, v_{r, a}$ is the probability of COVID-positivity for race $r$ and age-group $a, c_{s, r, a}$ is the prevalence of chronic condition $c$ among race $r$ and age-group $a$ in state $s, h_{c, a}$ is the probability of hospitalization for individuals of agegroup $a$ with chronic condition $c, h_{n o c, a}$ is the probability of hospitalization for individuals of age-group $a$ without the chronic condition $c$, and $i_{r, a}$ is the probability of ICU admission for race $r$ and age-group $a$. Total COVID-19 related hospitalization and ICU admissions at certain level (age-group and race or any combination) are obtained by aggregating $H_{s, r, a}$ and $I C U_{s, r, a}$ over appropriate levels, i.e., age-groups, race, and/or state.

\section{Data}

Estimating the model requires population and chronic condition prevalence data by state, race, and age-group. We used bridged-race postcensal population estimates of 2019 from the National Vital Statistics Systems [17]. The status quo chronic condition prevalence data were obtained from the 2019 Behavioral Risk Factor Surveillance System (BRFSS) data [18].

Data on the number of COVID-19 tests performed in age $18+$ population across states were obtained from the Center for Disease Control and Prevention's (CDC) COVIDView and CDC COVID Data Tracker websites $[19,20]$. Data on the number of COVID-19 positive cases as of December 26, 2020 and age distribution of the cases were obtained from the CDC COVID Data Tracker website [20]. The probabilities of COVID-positivity by race and age-group were calculated using estimates from Rentsch et al. (2020) [21] and Vahidy et al. (2020) [22], two studies providing complementary information on the racial and ethnic characteristics of COVID-19 test recipients in the USA by age groups.

The cumulative COVID-19 hospitalization rates by agegroup as of January 02, 2021 were obtained from the CDC's COVID-NET website [23]. Hospitalization per positive case was calculated by dividing the cumulative hospitalization rate per 100,000 adult population by the cumulative incidence rate per 100,000 adult population. Probabilities of hospitalization by chronic condition were calculated using the estimates from Yehia et al. (2020) [24], adjusted by the hospitalization per positive case for respective age-groups. Figure 2 shows the hospitalization probabilities that were used in the model estimation, by age-group and with and without the chronic condition. The ICU admission data were obtained from the CDC COVID-NET website [23]. ICU admission probabilities by race and age-group were calculated using conditional probability with multiple conditions. Figure 3 shows the ICU admission probabilities that were used in the model estimation, by age-group and race.

\section{Model estimation}

We first estimated a baseline for each of the three chronic conditions - hypertension, diabetes, and CVD, using the status quo level of prevalence (i.e., actual prevalence in 2019) of respective condition. The baseline estimates (for hypertension, diabetes, and CVD) replicate the cumulative hospitalization rate from March 07, 2020 to January 02, 2021 as reported in the COVID-NET data. Next, we estimated an alternative scenario of a lower prevalence, meaning number of adults with chronic condition be lower the that in the status quo, for each of the three 

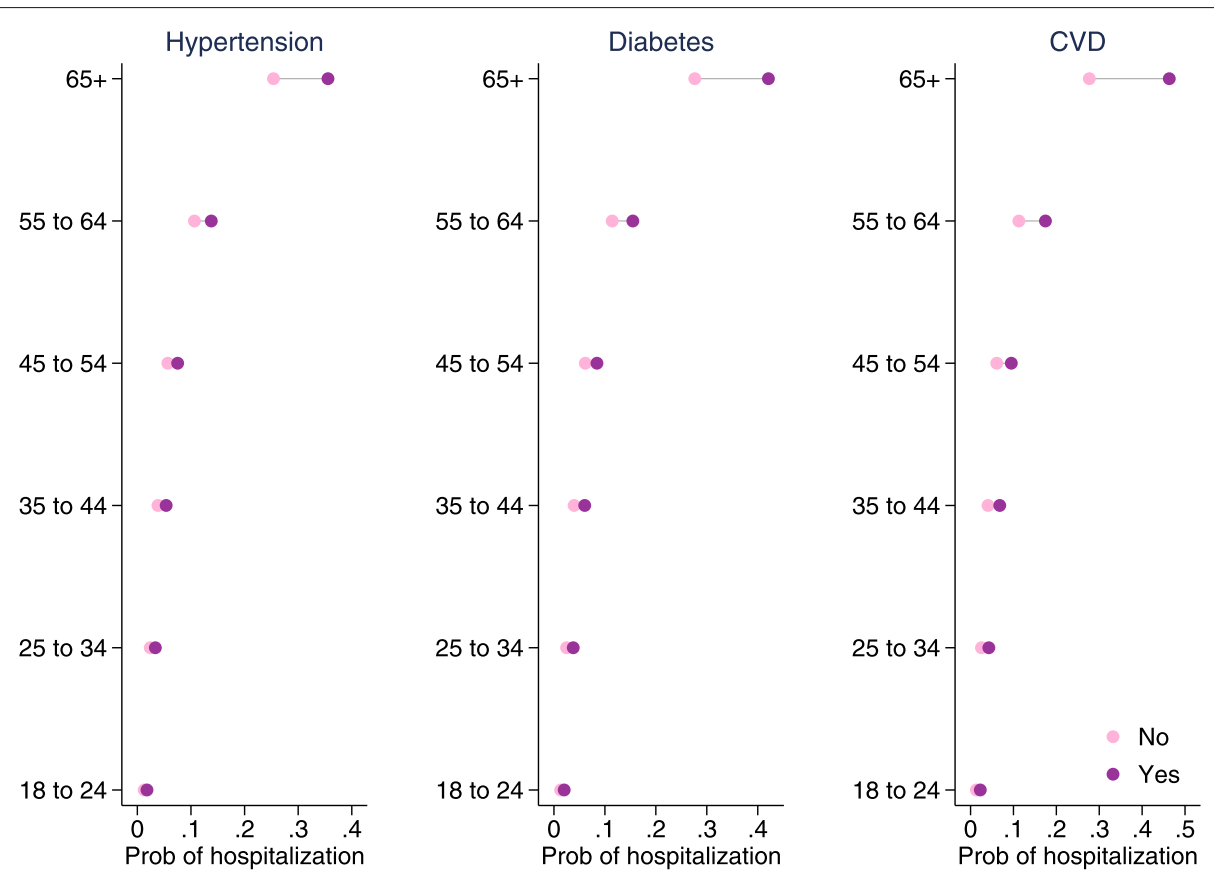

Fig. 2 Hospitalization probability by age-group and underlying chronic condition. Source: Authors' calculation from Yehia et al. (2020) and CDC data (The COVID-19-Associated Hospitalization Surveillance Network hospitalization data). The following formula is used to obtain probability of hospitalization by age for those not having chronic condition c: $p_{a}\left(\right.$ hospitalization|noc) $=1+\left[1-\frac{p \text { (hospitalization|c)) }}{p \text { (hospitalization|noc) }}\right] * p_{a}$ (hospitalization|COVID) *scalefactor $r_{c, a}$. A chronic-condition-age specific scale factor is included in the equation for adjustments in the probabilities that culminate in replication of the reported cumulative hospitalization rate. The following formula is used to obtain probability of hospitalization by age for those having chronic condition $c: p_{a}($ hospitalization $\mid c)=p_{a}($ hospitalization $\mid$ noc $) * \frac{p(\text { hospitalization } \mid c)}{p(\text { hospitalization } \mid \text { noc })}$

chronic conditions. The World Health Organization, in 2013, adopted a global action plan to reduce the "preventable and avoidable" burden of noncommunicable diseases (NCDs) by 2025. The plan outlined voluntary targets such as a $25 \%$ relative reduction in premature mortality

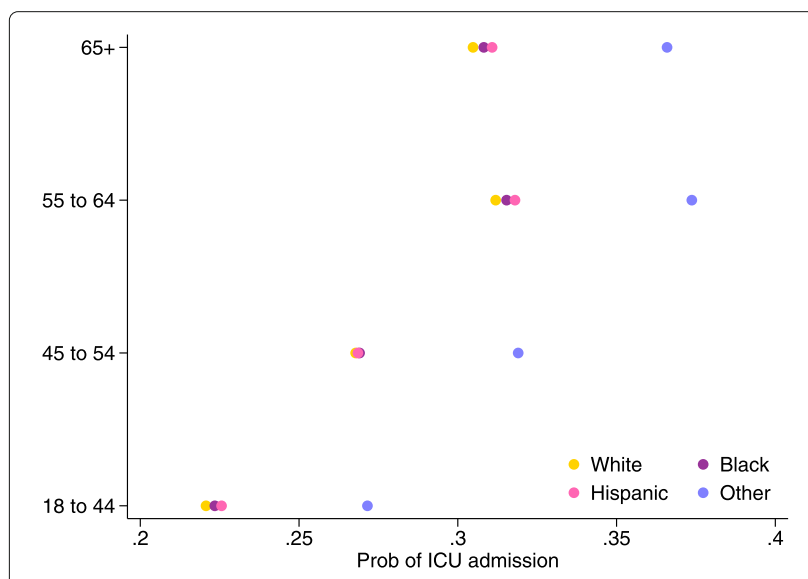

Fig. 3 ICU admission probability by age-group and race. Source: Authors' calculation from the CDC data (The COVID-19-Associated Hospitalization Surveillance Network hospitalization data). The following formula is used to obtained the conditional probabilities: $P($ ICUIRace\&Age $)=$ $\stackrel{=}{P(\text { Racel|ICU)P(Age||CU)P(ICU) }}$

$\overline{P(\text { Race } \mid / C U) P(A g e|| C U) P(I C U)+P(\text { Race|Non/CU) } P(\text { Age| NonlCU) } P(\text { NonlCU) }}$ from NCDs including CVD and diabetes, and a 25\% relative reduction in the prevalence of raised blood pressure or hypertension from the 2010 (baseline) level [25]. The prevalence trajectory, aiming the relative reduction target in 2025, serves as an alternative prevalence scenario for assessing what could have been the hospitalization and ICU admission rates under the lower prevalence rates. Though no prevalence-reduction target was set for diabetes and CVD, in the same vein as for the hypertension, we considered a $25 \%$ relative reduction in prevalence for these two conditions.

Figure 4 illustrates the prevalence rates of hypertension, diabetes, and CVD in the US adult (18+) population. The alternate hypertension prevalence (on the $25 \%$ relative reduction target trajectory) in 2019 would have been $26.71 \%$, which is $17.87 \%$ lower than the actual prevalence of $32.52 \%$. The alternate prevalence rates of diabetes and CVD would have been $8.20 \%$ and $7.04 \%$ respectively, which are $26.03 \%$ and $17.35 \%$ lower than the actual rates in 2019 (Fig. 4). After estimating the baseline, we re-estimate the model using these alternate prevalence rates for respective chronic conditions. We report the hospitalization and ICU admission rate per 100,000 adult population in the baseline and the differences in rates between the alternative scenario and the baseline. A 

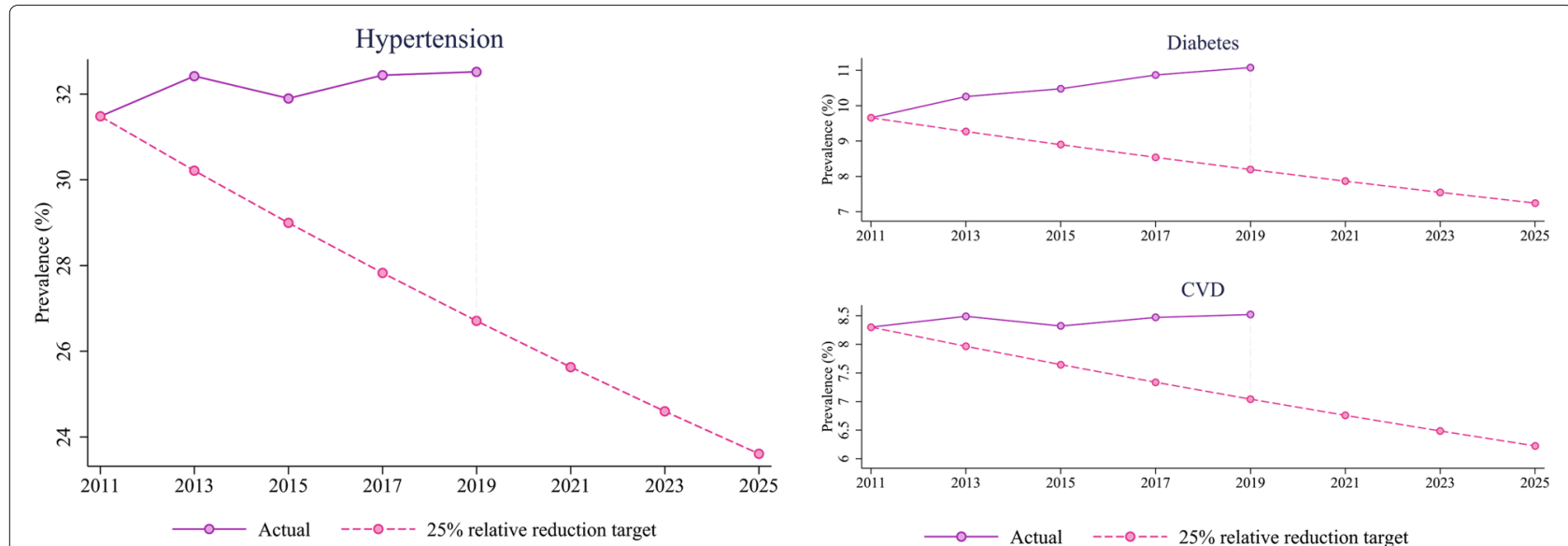

Fig. 4 Actual and alternative prevalence trend. The 2025-target prevalence is $75 \%$ of the prevalence in 2011. Compound biannual growth rate was used to construct the 25\% relative reduction target trajectory from 2011 to 2025

negative difference refers to a decrease from the baseline. We report the results by race and age-group aggregated over the states. We also report the differences in hospitalization and ICU admission rates by state.

\section{Results}

During the year 2020 (from March 7, 2020 to January 2, 2021), the cumulative hospitalization rate (in 18+ population) per 100,000 adults in the COVID-NET database was 466.7 [23]. Our baseline estimates of hospitalization rate (for hypertension, diabetes, and CVD) approximately replicates this reported rate. Table 1 presents the baseline hospitalization rate estimates by race and age-group and the change in hospitalization rate under the alternative scenario. For the hypertension scenario, had there been $17.87 \%$ less hypertensive adults (than status quo), the hospitalization rate would have been lowered by about 12 points (2.6\%). The biggest changes would have occurred for the older age-groups ( 55 and above) and for the Black population. The findings are similar for the diabetes and CVD scenarios as well, though in a lesser magnitude. Had there been $26.03 \%$ less adults with diabetes (than status quo), the overall cumulative hospitalization rate would have been $0.6 \%$ lower. However, among the nonWhite population, the rates would have been more than $2 \%$ lower. In case of CVD, had the prevalence been $17.35 \%$ lower (than status quo), the overall cumulative hospitalization rate would have been $1.4 \%$ lower.

The cumulative ICU admission rate estimates are presented in Table 2. Similar to the hospitalization results, the changes were larger for the older age cohorts (particularly age 65+). For hypertension and diabetes, a decline in prevalence would have resulted in a comparatively greater decline in ICU admission among the Black. For CVD, the decline, however, would have been relatively smaller
(1.1\%) among the Hispanic, and similar (around 1.5\%) for the White, Black and other race categories.

Table 3 presents the changes in cumulative hospitalization and ICU admission rates by state. In the case of hypertension, around $70 \%$ of the states would have more than 10 points lower cumulative hospitalization rate per 100,000 adults if hypertension prevalence were lower. The largest changes (more than 3\%) would have occurred in Mississippi, Alabama, West Virginia, Louisiana, Kentucky, and Arkansas. The lowest decline would have been in Utah, Colorado, Minnesota, and California. For diabetes, the decrease in cumulative hospitalization rate would have been the largest (more than 2.5\%) in Mississippi and West Virginia and the lowest in Alaska, Montana, and Vermont. Around one-fourth of the states would have experienced a more than 10 points lower cumulative hospitalization rate if the diabetes prevalence were lower. For CVD, the decrease in cumulative hospitalization rate would have been the highest for West Virginia (more than 2\%) and the lowest for Colorado, Alaska, and Utah (around 1\%). For lower CVD prevalence, the cumulative hospitalization rate would have been more than 5 points lower in more than $70 \%$ of the states. The changes in cumulative ICU admission rates were also similar to the changes in cumulative hospitalization rates for all three chronic conditions.

\section{Discussion}

In this study, we developed an analytical model to link the population level chronic conditions with COVID-19 related hospitalization and ICU admission in the USA. Based on the differential probability of being admitted to hospital from COVID-19 related complications with and without an underlying chronic condition, the model estimates cumulative hospitalization rate and subsequent 
Table 1 Cumulative hospitalization rate estimates

\begin{tabular}{|c|c|c|c|c|c|c|c|c|c|c|}
\hline & \multicolumn{5}{|c|}{ Hospitalization Rate (per 100,000 ) } & \multicolumn{5}{|c|}{$\Delta$ Hospitalization Rate (per 100,000 ) } \\
\hline & White & Black & Hispanic & Other & All & White & Black & Hispanic & Other & All \\
\hline \multicolumn{11}{|l|}{ Hypertension } \\
\hline 18 to 24 & 60 & 136.3 & 153.5 & 65.7 & 93.1 & -0.3 & -0.7 & -0.8 & -0.3 & -0.5 \\
\hline 25 to 34 & 115 & 265.4 & 295 & 124.9 & 175.3 & -1.1 & -2.7 & -2.1 & -0.7 & -1.5 \\
\hline 35 to 44 & 173.4 & 412.8 & 448.2 & 267.3 & 269.7 & -2.3 & -7.4 & -4.9 & -3.3 & -3.6 \\
\hline 45 to 54 & 226.7 & 555 & 603.2 & 399.8 & 346.9 & -3.8 & -13.1 & -9.3 & -5.6 & -6.1 \\
\hline 55 to 64 & 367.9 & 921.5 & 1012.2 & 771.8 & 534.6 & -7.5 & -26.7 & -21.1 & -15.5 & -11.9 \\
\hline $65+$ & 814.4 & 2041.3 & 2249 & 1992.6 & 1115.2 & -27.4 & -83.9 & -76.1 & -67.1 & -39 \\
\hline All & 359.4 & 700.2 & 658.3 & 582.7 & 467.1 & -9.5 & -21.4 & -14.2 & -14.7 & -12.1 \\
\hline$\%$-change & & & & & & -2.6 & -3.1 & -2.2 & -2.5 & -2.6 \\
\hline \multicolumn{11}{|l|}{ Diabetes } \\
\hline 18 to 24 & 60.3 & 137.6 & 154.8 & 66.3 & 93.8 & -0.1 & -0.3 & -0.2 & -0.1 & -0.1 \\
\hline 25 to 34 & 113.4 & 262.4 & 296.2 & 125.5 & 174.3 & -0.2 & -1 & -1.1 & -0.2 & -0.5 \\
\hline 35 to 44 & 169 & 397.4 & 449.2 & 263.9 & 265 & -0.9 & -3.7 & -3.9 & -1.8 & -2 \\
\hline 45 to 54 & 230 & 552 & 632.8 & 412.6 & 354.7 & -2 & -8.1 & -9.5 & -3.6 & -4.2 \\
\hline 55 to 64 & 367.5 & 904.3 & 1045.4 & 786.6 & 537.1 & -4.6 & -19.7 & -22.3 & -13.3 & -9 \\
\hline $65+$ & 793 & 2016.2 & 2356.9 & 2007.4 & 1106.4 & -19.1 & -79.4 & -96.8 & -64.3 & -33.8 \\
\hline All & 353.5 & 690 & 679.9 & 588.8 & 466.1 & -6.2 & -17.7 & -16.1 & -13.2 & -3 \\
\hline$\%$-change & & & & & & -1.7 & -2.6 & -2.4 & -2.2 & -0.6 \\
\hline \multicolumn{11}{|l|}{ CVD } \\
\hline 18 to 24 & 61.8 & 140.8 & 159.6 & 68 & 96.4 & -0.1 & -0.1 & -0.3 & -0.1 & -0.1 \\
\hline 25 to 34 & 116.3 & 269.5 & 303 & 129.2 & 178.6 & -0.2 & -0.8 & -0.6 & -0.2 & -0.3 \\
\hline 35 to 44 & 173 & 402 & 454.1 & 269.2 & 269.4 & -0.6 & -1.6 & -1.5 & -1 & -0.9 \\
\hline 45 to 54 & 227.8 & 542.1 & 611.8 & 408.2 & 348.1 & -1.3 & -4.6 & -3.7 & -2.4 & -2.2 \\
\hline 55 to 64 & 366 & 886.9 & 998.4 & 785.4 & 528.4 & -3.7 & -12.2 & -9.2 & -10.6 & -5.8 \\
\hline $65+$ & 822.1 & 1955.3 & 2219.4 & 2014.3 & 1111.7 & -17.6 & -41.9 & -40.2 & -43.6 & -23.2 \\
\hline All & 361.5 & 678.9 & 658.8 & 591.1 & 466.5 & -5.5 & -9.7 & -6.7 & -9.1 & -6.5 \\
\hline$\%$-change & & & & & & -1.5 & -1.4 & -1 & -1.5 & -1.4 \\
\hline
\end{tabular}

ICU admission rate per 100,000 adult population. The baseline, which replicates the cumulative hospitalization rate in the USA during the year 2020, is estimated using the status quo prevalence of the chronic condition in the US adult population. The counterfactual scenarios are estimated for a lower level (than status quo) of prevalence and compared with the baseline to illustrate what could have been the cumulative hospitalization rate had there been a lower prevalence of the chronic condition.

The model provides estimates by age group and race for three major chronic conditions in the US population hypertension, diabetes, and CVD. The findings quantify the lower number of COVID-19 related hospitalization and subsequent ICU admission in the USA if the prevalence of the chronic conditions would have been lower. We should point out that the cumulative effect of reducing prevalence rates of multiple chronic conditions on hospitalization and ICU admission will not necessarily be additive due to the correlations and interactions among the conditions. The decrease in hospitalization and ICU admission would have been relatively higher among the non-whites, who were disproportionately affected by the pandemic. The model, thus, generates evidence on the importance of prevention, control, and management of chronic conditions to lessen the overwhelming economic and public health burden on health systems.

The risks of chronic conditions like heart diseases, hypertension and diabetes are associated with lifestyle behaviors including but not limited to smoking, unhealthy diet, lack of physical activity, and excessive alcohol consumption [1]. Modifying these risky behaviors could reduce the prevalence of chronic conditions in the population. By quantifying the magnitude of the counterfactual hospitalization and ICU admission rates, our estimates analytically document that a lower (than status quo) population level prevalence of the major chronic conditions would have reduced the stress on the health system during the COVID-19 pandemic. Our analyses thus underpin 
Table 2 Cumulative ICU admission rate estimates

\begin{tabular}{|c|c|c|c|c|c|c|c|c|c|c|}
\hline & \multicolumn{5}{|c|}{ Hospitalization Rate (per 100,000) } & \multicolumn{5}{|c|}{$\Delta$ Hospitalization Rate (per 100,000 ) } \\
\hline & White & Black & Hispanic & Other & All & White & Black & Hispanic & Other & All \\
\hline \multicolumn{11}{|l|}{ Hypertension } \\
\hline 18 to 24 & 13.2 & 30.5 & 34.6 & 17.8 & 21 & -0.1 & -0.2 & -0.2 & -0.1 & -0.1 \\
\hline 25 to 34 & 25.4 & 59.3 & 66.6 & 33.9 & 39.6 & -0.2 & -0.6 & -0.5 & -0.2 & -0.3 \\
\hline 35 to 44 & 38.3 & 92.2 & 101.1 & 72.6 & 61.3 & -0.5 & -1.7 & -1.1 & -0.9 & -0.8 \\
\hline 45 to 54 & 60.7 & 149.3 & 162 & 127.6 & 94.6 & -1 & -3.5 & -2.5 & -1.8 & -1.6 \\
\hline 55 to 64 & 114.8 & 290.6 & 321.9 & 288.4 & 170.8 & -2.3 & -8.4 & -6.7 & -5.8 & -3.8 \\
\hline $65+$ & 248.2 & 629.1 & 699 & 729.1 & 348.3 & -8.4 & -25.9 & -23.6 & -24.6 & -12.2 \\
\hline All & 104.5 & 200.9 & 185.4 & 202.7 & 136.9 & -2.8 & -6.4 & -4.2 & -5.3 & -3.7 \\
\hline \%-change & & & & & & -2.7 & -3.2 & -2.3 & -2.6 & -2.7 \\
\hline \multicolumn{11}{|l|}{ Diabetes } \\
\hline 18 to 24 & 13.3 & 30.7 & 34.9 & 18 & 21.2 & 0 & -0.1 & 0 & 0 & 0 \\
\hline 25 to 34 & 25 & 58.6 & 66.8 & 34.1 & 39.4 & 0 & -0.2 & -0.2 & -0.1 & -0.1 \\
\hline 35 to 44 & 37.3 & 88.8 & 101.3 & 71.7 & 60.2 & -0.2 & -0.8 & -0.9 & -0.5 & -0.4 \\
\hline 45 to 54 & 61.6 & 148.5 & 169.9 & 131.6 & 96.7 & -0.5 & -2.2 & -2.5 & -1.2 & -1.1 \\
\hline 55 to 64 & 114.6 & 285.2 & 332.4 & 293.9 & 171.6 & -1.4 & -6.2 & -7.1 & -5 & -2.9 \\
\hline $65+$ & 241.7 & 621.4 & 732.5 & 734.5 & 345.7 & -5.8 & -24.5 & -30.1 & -23.5 & -10.6 \\
\hline All & 102.8 & 198.1 & 191.9 & 204.9 & 136.6 & -1.9 & -5.4 & -4.9 & -4.8 & -2.1 \\
\hline \%-change & & & & & & -1.8 & -2.7 & -2.5 & -2.3 & -1.5 \\
\hline \multicolumn{11}{|l|}{ CVD } \\
\hline 18 to 24 & 13.6 & 31.5 & 36 & 18.5 & 21.8 & 0 & 0 & -0.1 & 0 & 0 \\
\hline 25 to 34 & 25.7 & 60.2 & 68.4 & 35.1 & 40.4 & 0 & -0.2 & -0.1 & -0.1 & -0.1 \\
\hline 35 to 44 & 38.2 & 89.8 & 102.4 & 73.1 & 61.2 & -0.1 & -0.4 & -0.3 & -0.3 & -0.2 \\
\hline 45 to 54 & 61 & 145.9 & 164.3 & 130.2 & 95 & -0.4 & -1.2 & -1 & -0.7 & -0.6 \\
\hline 55 to 64 & 114.2 & 279.7 & 317.5 & 293.5 & 168.8 & -1.1 & -3.9 & -2.9 & -3.9 & -1.9 \\
\hline $65+$ & 250.6 & 602.6 & 689.8 & 737 & 347.3 & -5.4 & -12.9 & -12.5 & -16 & -7.3 \\
\hline All & 105.1 & 194.4 & 185.1 & 205.6 & 136.6 & -1.7 & -2.9 & -2 & -3.3 & -2 \\
\hline \%-change & & & & & & -1.6 & -1.5 & -1.1 & -1.6 & -1.5 \\
\hline
\end{tabular}

the need for an effective population level chronic disease management for avoiding undue burden on the health system.

Of note, our knowledge on the relationship between COVID-19 severity and underlying health conditions, however, are constantly evolving. Several studies report that elevated glycated hemoglobin (HbA1c) was associated with higher risk of severe COVID-19 outcomes and hospitalization [26, 27]. Other studies find that state of glycemic control after admission has critical association with outcomes in COVID-19 patients [28, 29]. Similarly, differing evidence was presented in different studies regarding the relationship between blood pressure control and outcomes among hospitalized COVID-19 patients [30-32]. Nevertheless, underlying chronic conditions are intrinsic to COVID-19 related hospitalization, and continued research will gradually shape our understanding of this critical issue.

Like other analytical models, our model has several limitations. First, based on the available information we can only model one chronic condition at a time. We do not have information on the relationship between hospitalization and multiple comorbidities. For example, we know the number of hospitalized cases having hypertension or diabetes, but do not know the number of hospitalized cases having hypertension only, or diabetes only, or both hypertension and diabetes. Therefore, we cannot distinguish between someone with hypertension only and someone with hypertension and other comorbidities. Second, the chronic condition prevalence was self-reported and not clinically diagnosed in the BRFSS data. Third, we extracted the parameter values, covering segment of population, from various studies and databases. We developed a proxy for the population level parameters with these subgroup estimates. For example, COVID-NET hospitalization data covers around $10 \%$ of the US population. Fourth, our model does not explicitly incorporate the individual level variations in health insurance coverage, which may impact hospitalization and ICU admission related to COVID-19. However, this aspect is implicitly 
Table 3 Change in cumulative hospitalization and ICU admission rates by state

\begin{tabular}{|c|c|c|c|c|c|c|c|c|c|c|c|c|}
\hline & \multicolumn{6}{|c|}{ Hospitalization Rate (per 100,000 ) } & \multicolumn{6}{|c|}{$\Delta$ Hospitalization Rate (per 100,000$)$} \\
\hline & \multicolumn{2}{|c|}{ Hypertension } & \multicolumn{2}{|c|}{ Diabetes } & \multicolumn{2}{|l|}{ CVD } & \multicolumn{2}{|c|}{ Hypertension } & \multicolumn{2}{|c|}{ Diabetes } & \multicolumn{2}{|l|}{ CVD } \\
\hline & $\Delta$ & $\%$ & $\Delta$ & $\%$ & $\Delta$ & $\%$ & $\Delta$ & $\%$ & $\Delta$ & $\%$ & $\Delta$ & $\%$ \\
\hline Alabama & -15.1 & -3.2 & -11.2 & -2.4 & -8.5 & -1.8 & -4.5 & -3.3 & -3.4 & -2.5 & -2.6 & -1.9 \\
\hline Alaska & -14.2 & -2.6 & -6.7 & -1.3 & -5.4 & -1 & -4.5 & -2.7 & -2.1 & -1.3 & -1.7 & -1.1 \\
\hline Arizona & -11.1 & -2.5 & -9.3 & -2.1 & -5.8 & -1.3 & -3.4 & -2.6 & -2.9 & -2.2 & -1.8 & -1.4 \\
\hline Arkansas & -12.3 & -3 & -9.5 & -2.4 & -7.6 & -1.9 & -3.7 & -3.1 & -2.9 & -2.4 & -2.3 & -1.9 \\
\hline California & -14 & -2.4 & -12.7 & -2.1 & -6.8 & -1.1 & -4.4 & -2.5 & -4 & -2.2 & -2.2 & -1.2 \\
\hline Colorado & -7.6 & -2.2 & -5.1 & -1.5 & -3.4 & -1 & -2.3 & -2.3 & -1.6 & -1.6 & -1 & -1.1 \\
\hline Connecticut & -15.5 & -2.5 & -11.2 & -1.8 & -6.8 & -1.1 & -4.7 & -2.6 & -3.4 & -1.9 & -2.1 & -1.2 \\
\hline Delaware & -18.6 & -2.8 & -15.9 & -2.3 & -9.9 & -1.5 & -5.6 & -2.8 & -4.8 & -2.4 & -3 & -1.5 \\
\hline DC & -19.1 & -2.7 & -15.8 & -2.2 & -9.8 & -1.4 & -5.8 & -2.8 & -4.8 & -2.4 & -3 & -1.5 \\
\hline Florida & -17 & -2.6 & -14.7 & -2.2 & -9.1 & -1.4 & -5.2 & -2.7 & -4.5 & -2.3 & -2.8 & -1.4 \\
\hline Georgia & -10.2 & -2.7 & -7.9 & -2.1 & -5.4 & -1.5 & -3.1 & -2.8 & -2.4 & -2.2 & -1.6 & -1.5 \\
\hline Hawaii & -14.4 & -2.7 & -10.6 & -2 & -6.5 & -1.2 & -5 & -2.8 & -3.7 & -2.1 & -2.2 & -1.3 \\
\hline Idaho & -6.5 & -2.4 & -5.3 & -2 & -3.6 & -1.4 & -1.9 & -2.5 & -1.6 & -2.1 & -1.1 & -1.4 \\
\hline Illinois & -11.8 & -2.7 & -9.6 & -2.2 & -6 & -1.4 & -3.6 & -2.8 & -3 & -2.3 & -1.9 & -1.5 \\
\hline Indiana & -9.7 & -2.7 & -7.9 & -2.3 & -5.6 & -1.6 & -2.9 & -2.8 & -2.4 & -2.4 & -1.7 & -1.7 \\
\hline lowa & -11.5 & -2.5 & -8.1 & -1.8 & -6.5 & -1.4 & -3.4 & -2.6 & -2.5 & -1.9 & -2 & -1.5 \\
\hline Kansas & -10.5 & -2.6 & -8 & -2 & -5.5 & -1.4 & -3.1 & -2.7 & -2.4 & -2.1 & -1.7 & -1.4 \\
\hline Kentucky & -10.9 & -3 & -8 & -2.3 & -6.7 & -1.8 & -3.3 & -3.1 & -2.4 & -2.4 & -2 & -1.9 \\
\hline Louisiana & -19.1 & -3 & -14.7 & -2.4 & -9.7 & -1.6 & -5.7 & -3.1 & -4.5 & -2.5 & -2.9 & -1.6 \\
\hline Maine & -8.8 & -2.7 & -5.6 & -1.7 & -5.3 & -1.6 & -2.6 & -2.7 & -1.7 & -1.8 & -1.6 & -1.7 \\
\hline Maryland & -19.5 & -2.7 & -14.4 & -2.1 & -8.4 & -1.2 & -5.9 & -2.8 & -4.4 & -2.2 & -2.6 & -1.3 \\
\hline Massachusetts & -13.4 & -2.4 & -9 & -1.6 & -7.4 & -1.3 & -4.1 & -2.5 & -2.8 & -1.7 & -2.3 & -1.4 \\
\hline Michigan & -10.5 & -2.7 & -7.9 & -2.1 & -6 & -1.6 & -3.2 & -2.8 & -2.4 & -2.1 & -1.8 & -1.6 \\
\hline Minnesota & -11.4 & -2.4 & -7.9 & -1.6 & -6.4 & -1.3 & -3.4 & -2.4 & -2.4 & -1.7 & -2 & -1.4 \\
\hline Mississippi & -8.6 & -3.3 & -7.2 & -2.8 & -4.5 & -1.7 & -2.5 & -3.3 & -2.2 & -2.9 & -1.4 & -1.8 \\
\hline Missouri & -5.4 & -2.5 & -4.2 & -1.9 & -3.5 & -1.6 & -1.6 & -2.6 & -1.3 & -2 & -1.1 & -1.7 \\
\hline Montana & -7.4 & -2.4 & -4.2 & -1.4 & -4.6 & -1.5 & -2.3 & -2.5 & -1.3 & -1.5 & -1.4 & -1.6 \\
\hline Nebraska & -10.9 & -2.5 & -8.1 & -1.9 & -6.1 & -1.4 & -3.3 & -2.6 & -2.5 & -2 & -1.8 & -1.5 \\
\hline Nevada & -13.7 & -2.5 & -11.7 & -2.1 & -7.6 & -1.4 & -4.2 & -2.6 & -3.7 & -2.2 & -2.4 & -1.4 \\
\hline New Hampshire & -7.1 & -2.5 & -4.4 & -1.6 & -3.6 & -1.3 & -2.1 & -2.6 & -1.3 & -1.6 & -1.1 & -1.3 \\
\hline New Mexico & -15.1 & -2.6 & -13.6 & -2.3 & -7.5 & -1.3 & -4.6 & -2.6 & -4.2 & -2.4 & -2.3 & -1.3 \\
\hline New York & -17.4 & -2.5 & -14.7 & -2.1 & -9.4 & -1.4 & -5.3 & -2.6 & -4.6 & -2.2 & -2.9 & -1.4 \\
\hline North Carolina & -12.1 & -2.8 & -9.1 & -2.1 & -6.7 & -1.5 & -3.6 & -2.9 & -2.8 & -2.2 & -2 & -1.6 \\
\hline North Dakota & -12.3 & -2.5 & -8.2 & -1.7 & -6.9 & -1.4 & -3.7 & -2.6 & -2.5 & -1.8 & -2.1 & -1.5 \\
\hline Ohio & -7.7 & -2.7 & -6.1 & -2.1 & -4.6 & -1.6 & -2.3 & -2.8 & -1.9 & -2.2 & -1.4 & -1.6 \\
\hline Oklahoma & -5.4 & -2.9 & -4.1 & -2.3 & -3.2 & -1.7 & -1.7 & -3 & -1.3 & -2.4 & -1 & -1.8 \\
\hline Oregon & -7.8 & -2.4 & -4.9 & -1.5 & -4.4 & -1.4 & -2.4 & -2.5 & -1.5 & -1.6 & -1.4 & -1.4 \\
\hline Pennsylvania & -10.9 & -2.7 & -7.9 & -2 & -6.5 & -1.6 & -3.3 & -2.8 & -2.4 & -2.1 & -2 & -1.7 \\
\hline Rhode Island & -15.3 & -2.6 & -11.4 & -2 & -7.8 & -1.3 & -4.6 & -2.7 & -3.5 & -2.1 & -2.4 & -1.4 \\
\hline South Carolina & -11.3 & -3 & -8.9 & -2.4 & -6.3 & -1.7 & -3.4 & -3.1 & -2.7 & -2.5 & -1.9 & -1.7 \\
\hline South Dakota & -6.1 & -2.5 & -4.7 & -2 & -3.5 & -1.4 & -1.9 & -2.6 & -1.5 & -2.1 & -1.1 & -1.5 \\
\hline Tennessee & -14.1 & -2.9 & -11.2 & -2.4 & -7.9 & -1.6 & -4.2 & -3 & -3.4 & -2.5 & -2.4 & -1.7 \\
\hline Texas & -10.3 & -2.6 & -9.3 & -2.3 & -5.6 & -1.4 & -3.1 & -2.7 & -2.8 & -2.5 & -1.7 & -1.5 \\
\hline Utah & -8.2 & -2.2 & -5.9 & -1.6 & -4 & -1.1 & -2.5 & -2.3 & -1.8 & -1.7 & -1.2 & -1.2 \\
\hline Vermont & -12.4 & -2.4 & -7.4 & -1.5 & -7.2 & -1.4 & -3.7 & -2.5 & -2.2 & -1.5 & -2.2 & -1.5 \\
\hline Virginia & -10.1 & -2.7 & -7.9 & -2.1 & -5 & -1.4 & -3.1 & -2.8 & -2.4 & -2.2 & -1.6 & -1.4 \\
\hline Washington & -4.7 & -2.4 & -3.3 & -1.8 & -2.7 & -1.4 & -1.4 & -2.5 & -1 & -1.9 & -0.8 & -1.5 \\
\hline West Virginia & -16.9 & -3.1 & -13.8 & -2.6 & -11.5 & -2.1 & -5.1 & -3.2 & -4.2 & -2.7 & -3.5 & -2.2 \\
\hline Wisconsin & -11.1 & -2.5 & -6.7 & -1.6 & -5.7 & -1.3 & -3.3 & -2.6 & -2.1 & -1.7 & -1.8 & -1.4 \\
\hline Wyoming & -10.4 & -2.5 & -6.6 & -1.6 & -5.8 & -1.4 & -3.1 & -2.6 & -2 & -1.7 & -1.8 & -1.5 \\
\hline
\end{tabular}


encompassed through the probabilistic differences in hospitalization outcome across state of residence, age, and racial groups. Fifth, we combined the American Indian, Asian, Native Hawaiian/ Pacific Islander, multiracial and other races in one race category because of relatively lower sample size (across states) of these race categories in the BRFSS data. A disaggregated analysis of these race categories would have produced a more nuanced understanding of this critical public health issue.

We deliver a model that encompasses the differences in population level chronic condition prevalence across state, race, and age group to estimate COVID-19 related hospitalization and ICU admission outcomes. We, however, do not evaluate the interplays between socioeconomic factors, race and ethnicity concerning chronic condition prevalence and COVID-19 related hospitalization. The estimated differences in change in hospitalization and ICU admission rates across racial groups and geographic territories can be further investigated in future research. At the individual level, COVID-19 related hospitalization is also associated with financial burden and risk of economic hardship [33, 34]. Future research can explore the extent of economic burden that could have been avoided if the prevalence of chronic conditions were lower.

Due to data unavailability, we could not assess how better management of chronic conditions could impact hospitalization and subsequent ICU admissions of COVID19 patients. For example, if we knew the share of individuals who have their hypertension under control in the status quo, then under appropriate assumptions, we could simulate alternate scenarios of enhanced hypertension control rate. Using fitting data, this can be studied in future research to showcase the importance of effective chronic condition management for preventing health system overwhelming during a pandemic.

\section{Conclusions}

Our model provides evidence on the importance of chronic disease management at the population level in order to lessen the overwhelming burden of the health system during a pandemic. Apart from studying COVID19 related mortality, a more objective outcome concerning population level underlying chronic conditions, we focus on the hospitalization and ICU admission, which are important indicators of health service delivery. We explore to what extent the population level chronic condition prevalence takes a toll on the health system capacity during the pandemic. The goal of this research is not to predict the number of hospitalization or ICU admission ex-ante, but to demonstrate how the numbers would have been lowered had there been a lower prevalence of the chronic condition (than status quo) in the population. The escalating number of COVID-19 related hospitalizations strains the health system and could have been significantly reduced by prevention and control of the major chronic conditions at the population level.

\section{Abbreviations}

CVD: Cardiovascular Disease; ICU: Intensive Care Unit; CDC: Centers for Disease Control and Prevention; NCDs: Non-communicable diseases; WHO: World Health Organization

\section{Authors' contributions}

BKD designed the study, conducted empirical analyses and prepared the first draft. BEA and VG critically reviewed the results and contributed in finalizing the manuscript. All authors read and approved the final manuscript.

\section{Funding}

None.

\section{Availability of data and materials}

The datasets generated and/or analysed during the current study are available in the National Vital Statistics System - Bridged-Race Population Estimates Data Files and Documentation (https://www.cdc.gov/nchs/nvss/bridged_ race/data_documentation.htm\#vintage2019), COVIDView (https://www.cdc. gov/coronavirus/2019-ncov/covid-data/covidview/01042021/specimenstested.html), CDC COVID Data Tracker (https://covid.cdc.gov/covid-datatracker/), and Behavioral Risk Factor Surveillance System (https://www.cdc. gov/brfss/annual_data/annual_2019.html) repository.

\section{Declarations}

Ethics approval and consent to participate

Not applicable since the study uses secondary data from publicly available sources.

\section{Consent for publication}

Not applicable.

\section{Competing interests}

The authors declare that they have no competing interests.

Received: 9 June 2021 Accepted: 4 January 2022

Published online: 01 February 2022

\section{References}

1. Centers for Disease Control and Prevention (CDC). About Chronic Diseases. Atlanta: CDC; 2020. https://www.cdc.gov/chronicdisease/ about/index.htm. Accessed 12 Jan 2021.

2. Centers for Disease Control and Prevention (CDC). Heart Disease and Stroke. Atlanta: CDC; 2020. https://www.cdc.gov/chronicdisease/ resources/publications/factsheets/heart-disease-stroke.htm. Accessed 12 Jan 2021

3. Centers for Disease Control and Prevention (CDC). National Diabetes Statistics Report 2020: Estimates of Diabetes and Its Burden in the United States. 2020. https://www.cdc.gov/diabetes/data/statistics-report/index. html. Accessed 12 Jan 2021

4. Ssentongo P, Ssentongo AE, Heilbrunn ES, Ba DM, Chinchilli VM. Association of cardiovascular disease and 10 other pre-existing comorbidities with covid-19 mortality: A systematic review and meta-analysis. PloS ONE. 2020;15(8):0238215.

5. Ko JY, Danielson ML, Town M, Derado G, Greenland KJ, Kirley PD, Alden NB, Yousey-Hindes K, Anderson EJ, Ryan PA, et al. Risk factors for covid-19-associated hospitalization: Covid-19-associated hospitalization surveillance network and behavioral risk factor surveillance system. Clin Infect Dis. 72(11):695-703.

6. Chang MH, Moonesinghe R, Truman BI. COVID-19 Hospitalization by Race and Ethnicity: Association with Chronic Conditions Among Medicare Beneficiaries, January 1-September 30, 2020. J Racial Ethn Health Disparities. 2021. https://doi.org/10.1007/s40615-020-00960-y.

7. Carrillo-Vega MF, Salinas-Escudero G, García-Peña C, Gutiérrez-Robledo LM, Parra-Rodríguez L. Early estimation of the risk factors for hospitalization and mortality by covid-19 in mexico. PLoS ONE. 2020;15(9):0238905 
8. Price-Haywood EG, Burton J, Fort D, Seoane L. Hospitalization and mortality among black patients and white patients with covid-19. N Eng J Med. 2020;382(26):2534-43.

9. Killerby ME, Link-Gelles R, Haight SC, Schrodt CA, England L, Gomes DJ, Shamout M, Pettrone K, O'Laughlin K, Kimball A, et al. Characteristics associated with hospitalization among patients with covid-19-metropolitan atlanta, georgia, march-april 2020. Morb Mortal Wkly Rep. 2020;69(25):790.

10. Garg S, Kim L, Whitaker M, O'Halloran A, Cummings $C$, Holstein R, Prill M, Chai SJ, Kirley PD, Alden NB, et al. Hospitalization rates and characteristics of patients hospitalized with laboratory-confirmed coronavirus disease 2019-covid-net, 14 states, march 1-30, 2020. Morb Mortal Wkly Rep. 2020;69(15):458.

11. Tian W, Jiang W, Yao J, Nicholson CJ, Li RH, Sigurslid HH, Wooster L, Rotter JI, Guo X, Malhotra R. Predictors of mortality in hospitalized covid-19 patients: A systematic review and meta-analysis. J Med Virol. 2020;92(10):1875-83.

12. Brownson RC, Chriqui JF, Stamatakis KA. Understanding evidence-based public health policy. Am J Public Health. 2009;99(9):1576-83.

13. Dong $E, D u H$, Gardner L. An interactive web-based dashboard to track covid-19 in real time. Lancet Infect Dis. 2020;20(5):533-4.

14. Dasgupta S, Bowen VB, Leidner A, Fletcher K, Musial T, Rose C, Cha A, Kang G, Dirlikov E, Pevzner E, et al. Association between social vulnerability and a county's risk for becoming a covid- 19 hotspot-united states, june 1-july 25, 2020. Morb Mortal Wkly Rep. 2020;69(42):1535.

15. Samanic CM, Barbour KE, Liu Y, Fang J, Lu H, Schieb L, Greenlund KJ. Prevalence of self-reported hypertension and antihypertensive medication use among adults_-united states, 2017. Morb Mortal Wkly Rep. 2020;69(14):393.

16. Kim L, Garg S, O'Halloran A, Whitaker $\mathrm{M}$, Pham H, Anderson EJ, Armistead I, Bennett NM, Billing L, Como-Sabetti K, et al. Risk factors for intensive care unit admission and in-hospital mortality among hospitalized adults identified through the us coronavirus disease 2019 (covid-19)-associated hospitalization surveillance network (covid-net). Clin Infect Dis. 2021;72(9):206-14.

17. National Center for Health Statistics (NCHS). Vintage 2019 postcensal estimates of the resident population of the United States (April 1, 2010, July 1, 2010-July 1, 2019), by year, county, single-year of age $(0,1,2, \ldots, 85$ years and over), bridged race, Hispanic origin, and sex. Atlanta: Centers for Disease Control and Prevention, NCHS; 2020. Prepared under a collaborative arrangement with the U.S. Census Bureau.

18. Centers for Disease Control and Prevention (CDC). 2019 Behavioral Risk Factor Surveillance System Survey Data. Atlanta: U.S. Department of Health and Human Services, CDC; 2020.

19. Centers for Disease Control and Prevention (CDC). COVIDView: A Weekly Surveillance Summary of U.S. COVID-19 Activity. Atlanta: CDC; 2020. https://www.cdc.gov/coronavirus/2019-ncov/covid-data/covidview/ 01042021/specimens-tested.html. Accessed 04 Jan 2021.

20. Centers for Disease Control and Prevention (CDC). CDC COVID Data Tracker. Atlanta: CDC; 2020. https://covid.cdc.gov/covid-data-tracker/. Accessed 13 Jan 2021

21. Rentsch CT, Kidwai-Khan F, Tate JP, Park LS, King Jr JT, Skanderson M, Hauser RG, Schultze A, Jarvis Cl, Holodniy M, et al. Patterns of covid-19 testing and mortality by race and ethnicity among united states veterans: A nationwide cohort study. PLoS Med. 2020;17(9):1003379.

22. Vahidy FS, Nicolas JC, Meeks JR, Khan O, Pan A, Jones SL, Masud F, Sostman HD, Phillips R, Andrieni JD, et al. Racial and ethnic disparities in sars-cov-2 pandemic: analysis of a covid-19 observational registry for a diverse us metropolitan population. BMJ Open. 2020;10(8):039849.

23. Centers for Disease Control and Prevention (CDC). COVID-NET: COVID-19-Associated Hospitalization Surveillance Network. Atlanta: CDC; 2020. https://gis.cdc.gov/grasp/COVIDNet/COVID19_3.html. Accessed 1 June 2021.

24. Yehia BR, Winegar A, Fogel R, Fakih M, Ottenbacher A, Jesser C, Bufalino A, Huang R-H, Cacchione J. Association of race with mortality among patients hospitalized with coronavirus disease 2019 (covid-19) at 92 us hospitals. JAMA Netw Open. 2020;3(8):2018039.

25. World Health Organization (WHO). Global action plan for the prevention and control of noncommunicable diseases 2013-2020. Geneva: WHO; 2013.
26. Merzon E, Green I, Shpigelman M, Vinker S, Raz I, Golan-Cohen A, Eldor R. Haemoglobin a1C is a predictor of covid-19 severity in patients with diabetes. Diabetes Metab Res Rev. 2021;37(5):3398.

27. Shauly-Aharonov M, Shafrir A, Paltiel O, Calderon-Margalit R, Safadi R, Bicher R, Barenholz-Goultschin O, Stokar J. Both high and low pre-infection glucose levels associated with increased risk for severe covid-19: New insights from a population-based study. Plos ONE. 2021;16(7):0254847.

28. Sardu C, D'Onofrio N, Balestrieri ML, Barbieri M, Rizzo MR, Messina V, Maggi P, Coppola N, Paolisso G, Marfella R. Outcomes in patients with hyperglycemia affected by covid-19: can we do more on glycemic control? Diabetes Care. 2020;43(7):1408-15.

29. Klonoff DC, Messler JC, Umpierrez GE, Peng L, Booth R, Crowe J, Garrett $V$, McFarland R, Pasquel FJ. Association between achieving inpatient glycemic control and clinical outcomes in hospitalized patients with covid-19: a multicenter, retrospective hospital-based analysis. Diabetes Care. 2021:44(2):578-85.

30. Sheppard JP, Nicholson BD, Lee J, McGagh D, Sherlock J, Koshiaris C, Oke J, Jones NR, Hinton W, Armitage L, et al. Association between blood pressure control and coronavirus disease 2019 outcomes in 45418 symptomatic patients with hypertension: an observational cohort study. Hypertension. 2021;77(3):846-55.

31. Caillon A, Zhao K, Klein KO, Greenwood CM, Lu Z, Paradis P, Schiffrin EL. High systolic blood pressure at hospital admission is an important risk factor in models predicting outcome of covid-19 patients. Am J Hypertens. 2021;34(3):282-90.

32. Tadic M, Saeed S, Grassi G, Taddei S, Mancia G, Cuspidi C. Hypertension and COVID-19: Ongoing Controversies. Front Cardiovasc Med. 2021;8: 639222. https://doi.org/10.3389/fcvm.2021.639222.

33. Eisenberg MD, Barry $C L$, Schilling $C L$, Kennedy-Hendricks A. Financial risk for covid-19-like respiratory hospitalizations in consumer-directed health plans. Am J Prev Med. 2020;59(3):445-8.

34. Di Fusco M, Shea KM, Lin J, Nguyen JL, Angulo FJ, Benigno M, Malhotra $D$, Emir B, Sung AH, Hammond $J$, et al. Health outcomes and economic burden of hospitalized covid-19 patients in the united states. J Med Econ. 2021;24(1):308-17.

\section{Publisher's Note}

Springer Nature remains neutral with regard to jurisdictional claims in published maps and institutional affiliations.

\section{Ready to submit your research? Choose BMC and benefit from:}

- fast, convenient online submission

- thorough peer review by experienced researchers in your field

- rapid publication on acceptance

- support for research data, including large and complex data types

- gold Open Access which fosters wider collaboration and increased citations

- maximum visibility for your research: over $100 \mathrm{M}$ website views per year

At $\mathrm{BMC}$, research is always in progress.

Learn more biomedcentral.com/submissions 